\title{
Comparative study of the prevalence of sepsis in patients admitted to dermatology and internal medicine wards ${ }^{*}$
}

\author{
Estudo comparativo da prevalência de sepse em pacientes internados nas \\ enfermarias de dermatologia e de clínica médica
}

\author{
Luiz Maurício Costa Almeida ${ }^{1}$ \\ Jackson Machado-Pinto ${ }^{4}$
}

\author{
Michelle dos Santos Diniz ${ }^{2}$ \\ Francisco Chagas Lima Silva ${ }^{5}$
}

Lorena dos Santos Diniz ${ }^{3}$

DOI: http://dx.doi.org/10.1590/abd1806-4841.20131912

\begin{abstract}
BACKGROUND: Sepsis is a common cause of morbidity and mortality among hospitalized patients. The prevalence of this condition has increased significantly in different parts of the world. Patients admitted to dermatology wards often have severe loss of skin barrier and use systemic corticosteroids, which favor the development of sepsis. OBJECTIVEs: To evaluate the prevalence of sepsis among patients admitted to a dermatology ward compared to that among patients admitted to an internal medicine ward. METHODs: It is a cross-sectional, observational, comparative study that was conducted at Hospital Santa Casa de Belo Horizonte. Data were collected from all patients admitted to four hospital beds at the dermatology and internal medicine wards between July 2008 and July 2009. Medical records were analyzed for the occurrence of sepsis, dermatologic diagnoses, comorbidities, types of pathogens and most commonly used antibiotics. Results: We analyzed 185 medical records. The prevalence of sepsis was $7.6 \%$ among patients admitted to the dermatology ward and $2.2 \%(p=0.10)$ among those admitted to the internal medicine ward. Patients with comorbidities, diabetes mellitus and cancer did not show a higher incidence of sepsis. The main agent found was Staphylococcus aureus, and the most commonly used antibiotics were ciprofloxacin and oxacillin. There was a significant association between sepsis and the use of systemic corticosteroids $(\mathrm{p}<0.001)$. ConcLusion: It becomes clear that epidemiological studies on sepsis should be performed more extensively and accurately in Brazil so that efforts to prevent and treat this serious disease can be made more effectively.
\end{abstract}

Keywords: Dermatology; Internal medicine; Sepsis; Systemic inflammatory response syndrome

Resumo: FundamenTos: A sepse é causa comum de morbimortalidade em pacientes internados. A sua prevalência está aumentando significativamente em diversas partes do mundo. Pacientes internados em enfermarias de dermatologia apresentam extensas áreas de perda da barreira cutânea, além de uso frequente de corticosteróides sistêmicos, condições favoráveis ao desenvolvimento de sepse. OBjETIVos: Avaliar a prevalência de sepse em pacientes internados em uma enfermaria de dermatologia e compará-la com a prevalência na enfermaria de clínica médica. MÉTODOS: Trata-se de estudo observacional transversal comparativo de análise de prontuários realizado na Santa Casa de Belo Horizonte. Foram coletados os dados de todos os pacientes internados em quatro leitos da clínica médica e da dematologia no período de julho de 2008 e julho de 2009. Foram analisados em busca da ocorrência de sepse, diagnósticos dermatológicas, comorbidades, tipos de patógenos mais associados e perfil de antibióticos mais utilizados. RESULTADOS: Foram analisados 185 prontuários e a prevalência de sepse entre os pacientes internados na enfermaria de dermatologia foi de 7,6\% e na enfermaria de clínica médica 2,2\% ( $p=0,10)$. Pacientes portadores de comorbidades, diabetes mellitus e neoplasias não demostraram maior ocorrência de sepse. O principal agente encontrado foi Staphylococcus aureus e os antibióticos mais utilizados foram ciprofloxacino e oxacilina. Houve significativa associação de sepse com o uso de corticosteróides sistêmicos ( $\mathrm{p}<0,001)$. ConcLusÃo: Torna-se claro que devem ser realizados estudos epidemiológicos mais amplos e acurados no Brasil sobre a sepse, para que os esforços na prevenção e no tratamento dessa grave doença possam ser direcionados de forma mais racional.

Palavras-chave: Dermatologia; Medicina interna; Sepse; Síndrome de resposta inflamatória sistêmica

Received on 05.06 .2012

Approved by the Advisory Board and accepted for publication on 12.12.2012.

Work conducted at Núcleo de Pós-Graduação e Pesquisa (Postgraduate and Research Center) - Santa Casa de Belo Horizonte - Belo Horizonte (MG), Brazil.

Conflict of interest: None

Financial funding: None

Dermatopathology Fellow at the University of Colorado USA, MSc in Medicine - Professor of Dermatology, College of Medical Sciences of Minas Gerais (Faculdade de Ciências Médicas de Minas Gerais - FCMMG); Preceptor of the Residency Program of Dermatology at Santa Casa de Belo Horizonte - Belo Horizonte (MG), Brazil.

MSc in Public Health, PhD in Adult Health (in progress) - Preceptor of the Residency Program of Dermatology at Santa Casa de Belo Horizonte - Belo Horizonte (MG), Brazil.

General Practitioner - Resident of General Surgery at San José Hospital - Belo Horizonte (MG), Brazil.

Specialist and MSc in Dermatology, Ph.D. in Medicine - Head of the Dermatology Clinic at Hospital Santa Casa de Belo Horizonte and of the Department of Dermatology, College of Medical Sciences of Minas Gerais (FCMMG), Belo Horizonte (MG), Brazil.

$\mathrm{PhD}$ in Infectious Diseases and Tropical Medicine, Federal University of Minas Gerais (UFMG) - Coordinator of the Postgraduate Program and Research of the Institute of Education and Research of Hospital Santa Casa de Belo Horizonte - Belo Horizonte (MG), Brazil. 


\section{INTRODUCTION}

Sepsis is an important cause of morbidity and mortality among hospitalized patients, despite the recent advances in supportive care and the specific treatments for this disease. It is defined as an infection with concurrent systemic manifestations, which are the result of the host response. This response, known as Systemic Inflammatory Response Syndrome (SIRS), can be diagnosed based on the presence of two or more of the following variables, according to the consensus statement established by the American College of Chest Physicians (ACCP) and the Society of Critical Care Medicine (SCCM) in 1992: ${ }^{1}$

a) Fever (temperature above $38^{\circ} \mathrm{C}$ ) or hypothermia (below $36^{\circ} \mathrm{C}$ );

b) Tachypnea (greater than 20 breaths per minute) or $\mathrm{PaCO}_{2}$ (partial pressure of carbon dioxide) less than $32 \mathrm{mmHg}$;

c) Tachycardia (above $90 \mathrm{bpm}$ );

d) Leukocytosis (above 12.000/ $/ \mathrm{L}$ ), leukopenia (below $4.000 / \mu \mathrm{L}$ ) or more than $10 \%$ immature neutrophils.

Thus, the presence of two or more criteria for SIRS in association with clinical and microbiological evidence of infection characterize sepsis. ${ }^{2}$

There are few and poor consistent data on the prevalence of sepsis among hospitalized patients in dermatology wards in Brazil. Brazil is a country of continental dimensions, with a heterogeneous population and unequal access to health care services. Private hospitals are usually better equipped and have more resources available than public hospitals, except for some public university hospitals. Measures to reduce the prevalence of sepsis and sepsis-related mortality must be addressed through reliable and consistent data on sepsis among the Brazilian population.

Inpatients in dermatology wards have often lost large areas of skin barrier, in addition to having impairment of the skin immune function. These patients, therefore, present conditions that are favorable to the development of sepsis. Frequent use of steroids and immunosuppressive drugs for prolonged periods of time accentuates the risk of sepsis in this group of patients. There is also a lack of data related to the epidemiological aspects and etiological profile of sepsis in this group. ${ }^{3}$

The objective of this paper is to evaluate the prevalence of sepsis among inpatients in a dermatology ward and compare it with the prevalence of sepsis in the internal medicine ward at Santa Casa de Belo Horizonte between 2008 and 2009. Moreover, we sought to identify the dermatologic conditions most frequently associated with the development of sepsis in the study sample, to indicate the most prevalent pathogens in sepsis in the sample, and to establish the possible association of comorbidities with diabetes mellitus and cancer and the development of sepsis.

\section{MATERIAL AND METHODS}

This is an observational, cross-sectional, comparative analysis of medical records carried out at Santa Casa de Belo Horizonte in the period between 2010 and 2011.

The sample calculation was based on estimates of the prevalence of sepsis in dermatology wards and ITUs, according to reference work. Therefore, based on these estimates, the considered prevalence was approximately $7 \%$ with a margin of error of $5 \%, 4,5$

We used a significance level of $5 \%$ (type I error) and power $80 \%$ (type II error). The final sample estimate was 141 patients (about 70 patients in each group).

All of the patients admitted to four beds (two female and two male) of the dermatology ward and four beds of the internal medicine ward (two female and two male) at Santa Casa de Belo Horizonte were randomly selected and included in the study carried out between July 2008 and July 2009, a total of 185 patients. From these, $93(50.3 \%)$ patients were admitted to the internal medicine ward and $92(49.7 \%)$ to the dermatology ward.

Patients younger than 12 years old were excluded, for it was a prerequisite for admission to the dermatology and internal medicine wards.

In this work, we used the 1992 SIRS definition, established by the ACCP and SCCM. ${ }^{1}$ Sepsis, a systemic response to an infection, was defined by the presence of SIRS combined with a documented infection, being considered positive with the isolation of germs through blood culture or in gram-positive peripheral blood sample. ${ }^{1}$

\section{Data collection}

Data were collected from April 2010 to March 2011 from the medical records of the patients included in the research and by filling out a form specially designed for the research.

This form showed the variables to be studied:

- Hospitalization Sector: Dermatology/Internal medicine ward.

- Date of birth, sex.

- Date of hospitalization, date of medical discharge.

- Reason for hospitalization, comorbidities.

- Medication in use; corticosteroids, type, dosage; immunossupressor, type, dosage; others.

- Antibiotics, type, treatment period. This item was subdivided in $\mathrm{A}, \mathrm{B}$ and $\mathrm{C}$ for patients using more 
than one type of antibiotic or when any change was made to the original scheme firstly proposed.

- SIRS/SEPSIS.

- Fever $\left(>38^{\circ} \mathrm{C}\right)$, hypothermia $\left(<36^{\circ} \mathrm{C}\right)$, tachycardia (above 90 bpm), tachypnoea (above 20 bpm), complete blood count showing leukocitosis $(>12,000)$ or leukopenia $(<4,000)$, hypotension.

- Cultures: blood culture, isolated germ, sensitivity and resistance; urine culture, isolated germ, sensitivity and resistance; secretion culture, isolated germ, sensitivity and resistance; other cultures, isolated germ, sensitivity and resistance.

The collected data were organized in Excel spreadsheets to be analyzed through pertinent statistical methods.

\section{Statistical Analysis}

Descriptive analysis of all variables used in the study was carried out by means of frequency distribution tables and central tendency measures and variability.

To check the differences between patients hospitalized in the internal medicine and dermatology wards, we used the Pearson's Chi-square test or Fisher's exact test, when comparing proportions. To compare the continuous variables, we used the MannWhitney's non-parametric test, suitable to the comparison between the two groups.

The same tests were used to evaluate the factors associated with the occurrence of sepsis in the univariate analysis. OR was also evaluated, with the respective CI of $95 \%$.

The variables selected for the multivariate model of binary logistic regression were those with $\mathrm{p}$ value below 0.20 in the univariate analysis. The foward method was used, with the variables being inserted one by one in the model, based on significance. For permanence of the variable in the final model, a $5 \%$ significance level ( $p$ value $<0.05$ ) was considered. The adjustment of the final model was evaluated through the Hosmer-Lemeshow statistical test. 6

The significance level of 5\% was considered in all of the analysis, with the adoption of the Statistical Package for Social Sciences (SPSS) 15.0.

The study protocol was approved by the Ethics Committee of the hospital where the study was conducted.

\section{RESULTS}

The number of inpatients in the dermatology ward was $92(49.7 \%)$, while it was $93(50.3 \%)$ in the internal medicine ward. A little more than half of the patients studied $(50.8 \%)$ were male.

Nine patients, that is, $4.9 \%$ of the total, presented sepsis. Diabetes was identified in 25 patients
(13.5\%); and $20(10.8 \%)$ presented cancer at hospital admission; SIRS was reported in 65 patients (35.1\%); community and nosocomial infections were detected in $88(47.6 \%)$ patients. The average age was 54 years, and the median was 55 years. The average hospital stay was 15 days, with a median of 11 days.

Twenty-two (22) of the studied patients (11.9\%) used systemic steroids during their hospital stay. Prednisone was used in almost the total number of cases $(95.5 \%)$, and the most frequent dosage was 40 $\mathrm{mg} /$ day $(30 \%)$. Three patients $(1.6 \%)$ used an immunossupressor, and only metothrexate was observed; the maximum dose was $15 \mathrm{mg} /$ week $(66.7 \%)$.

A hundred and ten (110) patients (59.4\%) used antibiotics (ATB), and the maximum number was five antibiotics. A total of 25 different types of antibiotics were used, and the most frequently used one was ciprofloxacin $(14.0 \%)$. In addition, in the 19 cases evaluated for the initial use of ATB, the antibiotic was not in accordance with culture in 10 cases $(52.6 \%)$ and was changed after culture in seven cases $(36.8 \%)$.

It is noteworthy that, out of the 12 cases which had no ATB change after culture, nine already belonged to the group whose antibiotic therapy had been introduced in accordance with culture. In the remaining three cases, the initial coverage, though empirical, was consistent with the desired coverage, and there was no need for changes in the antibiotic profile.

According to table 1, blood culture was performed in 22 patients $(11.9 \%)$, with positive results and germ identification in seven (3.8\%). Research for bacteria per gram of peripheral blood was positive in nine $(40.9 \%)$ out of 22 cases. Urine culture and secretion culture were required in 22 patients $(11.9 \%)$, with germ identification in seven $(3.8 \%)$ urine cultures and in eight $(4.2 \%)$ secretion cultures. In addition, the germs identified in each test were Escherichia coli ( $E$. coli), the most common germ found in the urine cultures, and S. aureus, the most common germ found in the secretion cultures.

According to the results showed in table 2, there was a statistically significant difference between inpatients from the internal medicine ward and those from the dermatology ward concerning prevalence of cancer, SIRS and age. Both cancer (neoplasia) and SIRS were more prevalent in the internal medicine ward (17.2\% and $47.3 \%$, respectively), compared with the dermatology ward (4.3 and $22.8 \%$, respectively). In addition, we found a higher mean and median age among inpatients from the internal medicine ward.

Besides that, there was a statistically significant difference between inpatients from the internal medicine ward and those from the dermatology ward in 
TABLE 1: Descriptive analysis of the variables related to blood culture, urine culture and secretion culture $(n=185)$

\begin{tabular}{|c|c|c|}
\hline & No. & Percentage \\
\hline \multicolumn{3}{|l|}{ Blood Culture } \\
\hline No & 163 & 88.1 \\
\hline Yes & 22 & 11.9 \\
\hline \multicolumn{3}{|l|}{ Bacteria in peripheral blood } \\
\hline Gram-negative & 13 & 59.1 \\
\hline Gram-positive & 9 & 40.9 \\
\hline \multicolumn{3}{|l|}{ Germ identified in blood culture } \\
\hline Staphylococcus spp. & 1 & 14.3 \\
\hline Staphylococcus aureus & 3 & 42.9 \\
\hline Coagulase-negative Staphylococcus & 2 & 28.6 \\
\hline Yeasts & 1 & 14.3 \\
\hline \multicolumn{3}{|l|}{ Uroculture } \\
\hline No & 163 & 88.1 \\
\hline Yes & 22 & 11.9 \\
\hline \multicolumn{3}{|l|}{ Bacteria in urine } \\
\hline Gram-negative & 19 & 90.5 \\
\hline Gram-positive & 2 & 9.5 \\
\hline \multicolumn{3}{|l|}{ Germ identified in uroculture } \\
\hline Pseudomonas & 1 & 14.3 \\
\hline Citrobacter freundii & 1 & 14.3 \\
\hline Proteus mirabilis & 1 & 14.3 \\
\hline Morganela morgani & 1 & 14.3 \\
\hline Escherichia coli & 3 & 42.9 \\
\hline \multicolumn{3}{|l|}{ Secretion culture } \\
\hline No & 163 & 88.1 \\
\hline Yes & 22 & 11.9 \\
\hline \multicolumn{3}{|l|}{ Bacteria in secretion culture } \\
\hline Gram-negative & 14 & 63.6 \\
\hline Gram-positive & 8 & 36.4 \\
\hline \multicolumn{3}{|l|}{ Germ identified in secretion culture } \\
\hline Acinetobacter baumannii & 1 & 6.7 \\
\hline Escherichia coli & 1 & 6.7 \\
\hline Klebsiela & 1 & 6.7 \\
\hline Proteus vulgaris & 4 & 26.7 \\
\hline Pseudomonas aeruginosa & 1 & 6.7 \\
\hline Pseudomonas spp. & 1 & 6.7 \\
\hline Staphylococcus aureus & 6 & 40.0 \\
\hline
\end{tabular}

relation to use of systemic steroids. Among the inpatients from the internal medicine ward, $2.2 \%$ used this kind of medication, while the percentage among dermatology inpatients was $21.7 \%$. There were no statistically significant differences between internal medicine and dermatology patients regarding number of antibiotics used.

Considering the univariate analysis, the factors that showed statistically significant association with the presence of sepsis were age and number of days in hospital ( $p$ value $<0.05$ ). The prevalence of sepsis was higher among inpatients from the dermatology $(7.6 \%)$ ward compared to that found among inpatients from the internal medicine ward (2.2\%); however, this association was not statistically significant $(\mathrm{p}=0.10)$.

After analyzing the association between sepsis and use of corticosteroids, we observed that the prevalence of sepsis among patients who did not use corticosteroids was $1.8 \%$, while it was $27.3 \%$ among those who used this medication. We also noted the association between occurrence of sepsis and amount of ATBs. With the increase use of ATB, the chance of occurrence of sepsis is 2.14 times higher. Blood culture and urine culture were performed more frequently among patients with sepsis, and this difference was statistically significant $(\mathrm{p}<0.05)$.

The use of the immunossupressor methotrexate (MTX) did not show a statistically significant association with sepsis $(p=0.140)$. However, it is noteworthy that one of the patients who had used MTX developed sepsis.

In table 3 , the patients were classified according to age group, hospitalization place and associated conditions. The use of corticosteroids was higher in all 
TABLE 2: Descriptive analysis of the variables place of admission, gender, sepsis, diabetes, SIRS, infection and neoplasm, age and number of days in hospital $(\mathrm{n}=195)$

\begin{tabular}{|c|c|c|c|c|c|}
\hline & \multicolumn{2}{|c|}{ Internal Medicine } & \multicolumn{2}{|c|}{ Dermatology } & \multirow[t]{2}{*}{ P value } \\
\hline & $\mathbf{N}$ & $\%$ & $\mathbf{N}$ & $\%$ & \\
\hline \multicolumn{6}{|l|}{ Gender } \\
\hline Male & 46 & $49.5 \%$ & 48 & $52.2 \%$ & \multirow[t]{2}{*}{$0.712^{*}$} \\
\hline Female & 47 & $50.5 \%$ & 44 & $47.8 \%$ & \\
\hline \multicolumn{6}{|l|}{ Sepsis } \\
\hline No & 91 & $97.8 \%$ & 85 & $92.4 \%$ & \multirow[t]{2}{*}{$0.100^{* *}$} \\
\hline Yes & 2 & $2.2 \%$ & 7 & $7.6 \%$ & \\
\hline \multicolumn{6}{|l|}{ Diabetes } \\
\hline No & 76 & $81.7 \%$ & 84 & $91.3 \%$ & \multirow{2}{*}{$0.057^{*}$} \\
\hline Yes & 17 & $18.3 \%$ & 8 & $8.7 \%$ & \\
\hline \multicolumn{6}{|l|}{ Neoplasm } \\
\hline No & 77 & $82.8 \%$ & 88 & $95.7 \%$ & \multirow[t]{2}{*}{$0.005^{*}$} \\
\hline Yes & 16 & $17.2 \%$ & 4 & $4.3 \%$ & \\
\hline \multicolumn{6}{|l|}{ SIRS } \\
\hline No & 49 & $52.7 \%$ & 71 & $77.2 \%$ & \multirow[t]{2}{*}{$<0.001^{*}$} \\
\hline Yes & 44 & $47.3 \%$ & 21 & $22.8 \%$ & \\
\hline \multicolumn{6}{|l|}{ Infection } \\
\hline No & 51 & $54.8 \%$ & 46 & $50.0 \%$ & \multirow[t]{2}{*}{0.510} \\
\hline Yes & 42 & $45.2 \%$ & 46 & $50.0 \%$ & \\
\hline \multicolumn{6}{|l|}{ Type of infection } \\
\hline 1 & 34 & $81.0 \%$ & 35 & $76.1 \%$ & \multirow[t]{2}{*}{0.580} \\
\hline 2 & 8 & $19.0 \%$ & 11 & $23.9 \%$ & \\
\hline \multicolumn{6}{|l|}{ Age } \\
\hline Average & \multicolumn{2}{|c|}{57.9} & \multicolumn{2}{|l|}{50.6} & \multirow{3}{*}{$0.008^{* *}$} \\
\hline Standard Deviation & \multirow{2}{*}{\multicolumn{2}{|c|}{20.5}} & \multicolumn{2}{|l|}{17.8} & \\
\hline Median & \multirow{2}{*}{\multicolumn{2}{|c|}{62.0}} & \multirow{2}{*}{\multicolumn{2}{|c|}{49.0}} & \\
\hline \multicolumn{2}{|c|}{ Number of days in hospital } & & & & \\
\hline Average & \multicolumn{2}{|c|}{16.9} & \multicolumn{2}{|l|}{12.6} & \multirow[t]{2}{*}{$0.094^{* * *}$} \\
\hline Standard Deviation & \multirow{2}{*}{\multicolumn{2}{|c|}{15.8}} & 9.3 & & \\
\hline Median & & & 10.0 & & \\
\hline
\end{tabular}

TABLE 3: Descriptive analysis of the variables place of admission, gender, sepsis, diabetes, SIRS, infection and neoplasm, age and number of days in hospital $(\mathrm{n}=195)$

\begin{tabular}{|c|c|c|c|c|c|c|c|c|c|c|c|c|c|c|c|c|c|c|c|c|}
\hline \multirow[b]{3}{*}{ Age group } & \multicolumn{9}{|c|}{ Internal Medicine } & \multicolumn{11}{|c|}{ Dermatology } \\
\hline & \multicolumn{2}{|c|}{ Diabetes } & \multicolumn{2}{|c|}{ Neoplasms } & \multicolumn{2}{|c|}{ Corticosteroid } & \multirow{2}{*}{$\begin{array}{l}\text { Days in } \\
\text { Hospital } \\
\text { median }\end{array}$} & \multicolumn{2}{|c|}{ subtotal } & \multicolumn{2}{|c|}{ Diabetes } & \multicolumn{2}{|c|}{ Neoplasms } & \multicolumn{2}{|c|}{ Corticosteroid } & \multirow{2}{*}{$\begin{array}{l}\text { Days in } \\
\text { Hospital } \\
\text { median }\end{array}$} & \multicolumn{2}{|c|}{ subtotal } & \multicolumn{2}{|c|}{ Total } \\
\hline & No. & $\%$ & No. & $\%$ & No. & $\%$ & & No & $\%$ & No. & $\%$ & No. & $\%$ & No. & $\%$ & & No. & $\%$ & No. & $\%$ \\
\hline 10 to 24 & 0 & 0.0 & 1 & 14.3 & 1 & 14.3 & 5.0 & 7 & 7.53 & 0 & 0.0 & 0 & 0.0 & 2 & 40.0 & 11.0 & 5 & 5.4 & 12 & 6.49 \\
\hline 25 to 40 & 1 & 9.1 & 1 & 9.1 & 1 & 9.1 & 8.0 & 11 & 11.8 & 2 & 9.1 & 0 & 0.0 & 8 & 36.4 & 11.5 & 22 & 24 & 33 & 17.8 \\
\hline 40 to 54 & 3 & 15.8 & 4 & 21.1 & 0 & 0.0 & 16.0 & 19 & 20.4 & 1 & 4.2 & 0 & 0.0 & 6 & 25.0 & 9.5 & 24 & 26 & 43 & 23.2 \\
\hline 55 to 69 & 6 & 30.0 & 4 & 20.0 & 0 & 0.0 & 11.5 & 20 & 21.5 & 4 & 17.4 & 0 & 0.0 & 2 & 8.7 & 10.0 & 23 & 25 & 43 & 23.2 \\
\hline 70 to 84 & 7 & 23.3 & 4 & 13.3 & 0 & 0.0 & 11.5 & 30 & 32.3 & 1 & 6.3 & 2 & 12.5 & 2 & 12.5 & 13.5 & 16 & 17 & 46 & 24.9 \\
\hline 85 or older & 0 & 0.0 & 2 & 33.3 & 0 & 0.0 & 10.5 & 6 & 6.5 & 0 & 0.0 & 2 & 100.0 & 0 & 0.0 & 11.0 & 2 & 2.2 & 8 & 4.32 \\
\hline Total & 17 & 18.3 & 16 & 17.2 & 2 & 2.2 & 12.0 & 93 & & 8 & 8.7 & 4 & 4.3 & 20 & 21.7 & 10.0 & 92 & & 185 & \\
\hline
\end{tabular}

age groups among the dermatology patients. There is a higher concentration of older patients in the internal medicine ward $(60.2 \%$ were over 55 years old) compared to the dermatology ward $(55.4 \%$ were under 55 years old).

Among the nine patients who had sepsis, two had diabetes and none had cancer (Table 4). Among the seven patients with a diagnosis of sepsis in the dermatology ward, five had bullous disease. The most frequently found germ in the blood cultures was $S$. aureus, which was found in three patients. Two cases were gram-positive, but there was no germ growth (confirming the diagnosis of sepsis, with no specific agent being isolated); and in one patient the found 
TABLE 4: Patients with sepsis classifided according to age, place of hospitalization, germ isolated in blood cultures and associated clinical conditions $(\mathrm{n}=9)$

\begin{tabular}{|c|c|c|c|c|c|c|c|}
\hline \multirow[t]{2}{*}{ Group } & \multicolumn{4}{|l|}{ Age } & \multicolumn{3}{|l|}{ Days in } \\
\hline & Group & Diabetes & Neoplasm & Corticosteroid & Hospital & Main Diagnosis & Germ in Blood Culture \\
\hline \multicolumn{8}{|l|}{ Internal } \\
\hline \multirow[t]{6}{*}{ Medicine } & 40 to 54 & Yes & No & No & 94 & Sinusitis & Coagulase-negative Staphylococcus \\
\hline & 10 to24 & No & No & No & 24 & Abdominal pain & - \\
\hline & & & & & & + peripalpebral swelling & \\
\hline & 10 to 24 & No & No & Yes & 20 & pemphigus foliaceus & Staphylococcus spp. \\
\hline & 70 to 84 & No & No & Yes & 33 & bullous pemphigoid & Staphylococcus aureus \\
\hline & 25 to 40 & No & No & Yes & 10 & pemphigus foliaceus & Staphylococcus aureus \\
\hline \multirow[t]{4}{*}{ Dermatology } & 55 to 69 & No & No & No & 10 & leprosy & Coagulase-negative Staphylococcus \\
\hline & 40 to 54 & No & No & Yes & 42 & pemphigus vulgaris & - \\
\hline & 25 to 40 & No & No & Yes & 24 & leprosy & Yeast \\
\hline & 25 to 40 & Yes & No & Yes & 43 & pemphigus vulgaris & Staphylococcus aureus \\
\hline
\end{tabular}

germ was Staphylococcus spp (possibly S. aureus). There was also one case of sepsis caused by fungi/yeast. Among all patients with sepsis, there was secretion culture of skin lesions in only two, and the germs found in these two cases were not the same as those found in the blood culture. In one patient with pemphigus foliaceus and sepsis by Staphylococcus spp, there was growth of Pseudomonas aeruginosa in the lesion secretion culture. In another patient with leprosy and sepsis caused by coagulase-negative Staphylococci, there was growth of Staphylococcus aureus.

After the multivariate analysis, the variables that remained in the final model as factors associated with the occurrence of sepsis were age, number of days in hospital and hospitalization place. With an increase of one year in age, there was reduction of 0.94 $(6 \%)$ in the chance of occurrence of sepsis. On the other hand, with an increase of one hospital day, the chance of sepsis increased $1.10(10 \%)$.

Finally, inpatients from the dermatology ward were almost 15 times more likely to have sepsis than those from the internal medicine ward in the multivariate analysis.

The multivariate analysis model had good adjustment according to the Hosmer-Lemeshow Statistical test $(p>0.05)$. When carrying out the model, collinearity was found between the variables "use of corticosteroids" and "hospitalization in dermatology", with the first being excluded from the final model. Among the patients that used corticoids, 90.9\% were hospitalized in the dermatology ward.

\section{DISCUSSION}

The groups evaluated and compared in this study were homogeneous concerning sex and number of patients. However, the patients admitted to the dermatology ward were younger. The mean and median ages of dermatology inpatients are probably lower compared to internal medicine inpatients, as the diseases that justify hospitalization in the dermatology ward are associated with lower ages compared to the most prevalent diseases in internal medicine. Tumors, for example, arise at markedly higher ages and are significantly more associated with hospitalization in the internal medicine ward. Pemphigus, which accounts for most admissions to the dermatology ward, have higher incidence among young adults and non-elderly. ${ }^{7}$

In the multivariate analysis, a higher chance of sepsis was found among younger patients, with reduction of $6 \%$ in the chance of sepsis with a oneyear increase. This was due to sepsis being more prevalent in dermatology patients, who present lower average age at hospital admission. This factor is part of the multivariate analysis for its weight to be hierarchical and properly compensated.

One of the noteworthy aspects of the results was the complete absence of requests for skin secretion or respiratory cultures in the internal medicine ward, with only urine cultures being requested. In dermatology, it is routine to request skin (cutaneous) secretion cultures and antibiogram. This might be a study limitation, as the dermatological examination of the inpatients from the internal medicine ward might have been neglected or the request of cultures of any lesions or skin secretions may not be routine.

The prevalence of SIRS observed in the studied group was significantly higher among patients from the internal medicine ward $(47.3 \%)$ when compared to the dermatology inpatients $(22.8 \%)$. The literature available usually refers to lower values for SIRS in inpatients from dermatology wards, but with some differences. Thomas et al. (2010) underscore an incidence rate of SIRS of only $2.4 \%$ among 2,765 patients. 8 These authors, however, evaluated patients admitted to a dermatology ward (721) and patients referred 
to dermatological evaluation by other departments in the same hospital (2044). In studies on the prevalence of SIRS among patients of internal medicine wards, the observed levels are around one third of the patients. These levels are below the findings in our sample, which had values similar to those of ITUs. It is possible that these data are due to the research being performed in a renowned tertiary care hospital to which the most severe cases are referred. ${ }^{9-11}$

The data confirm that the patients in the dermatology ward $(21.7 \%)$ are around 10 times more likely to use corticosteroids than the patients in the internal medicine ward $(2.2 \%)$. The association between sepsis and use of corticosteroids was also statistically positive, with $p<0.001$. The prevalence of sepsis among patients that had not used corticoids was just $1.8 \%$, while it was $27.3 \%$ among those that used the medication. This factor (use of corticoids) was so closely associated with hospitalization in the dermatology ward that its permanence was avoided in the multivariate analysis model.

Many admissions to the dermatology ward are motivated by autoimmune bullous diseases that require, among other drugs, high doses of corticosteroids for prolonged periods of time. Despite immunossupression and consequent higher risk of sepsis (in addition to other important side effects), the use of these drugs dramatically reduced mortality from pemphigus after its introduction in the $50 \mathrm{~s} .{ }^{12}$ Ahmed and Moy (1982) investigated the death causes of 13 patients with pemphigus between 1965 and 1980. All of them were using high doses of corticosteroids for prolonged periods of time. Infection was the most common cause of death. ${ }^{13}$

The hospital stay period for patients with sepsis was longer than that for patients who did not present this condition, with a statistically significant difference $(p<0.001 \%)$. A one-day increase in hospital stay raised the chance of developing sepsis to $10 \%$. This point can be evaluated in two different ways. First, longer hospital stays, in many cases with impairment of the skin barrier and frequent use of immunossupressors, become a significant risk factor for infections. On the other hand, patients with sepsis require more care and must remain hospitalized for longer periods of time for treatment of the disease. ${ }^{14-16}$

Although cancer and diabetes mellitus increase the risk of infections, these combinations were not positive in our study. ${ }^{17-18}$ There was no increased risk of sepsis among these patients. Among the nine patients that developed sepsis, only two had diabetes and none had cancer. Among sepsis and cancer-related factors, a major determinant is the stage of the neoplasm and, consequently, the patient's general status. Patients with more severe or terminal courses of the disease are more likely to have sepsis. ${ }^{19}$

Patients with bullous diseases were often more likely to develop sepsis in accordance with other authors' findings. ${ }^{14}$ Of the seven patients with sepsis evaluated in the dermatology ward, five had bullous diseases. The two patients with sepsis and whose main diagnosis was leprosy presented reactional effect, with large areas of skin ulcerations, and used corticosteroids. Other authors have also showed occurrence of sepsis in patients with leprosy. ${ }^{20}$

Of the nine patients that had sepsis, it was only possible to identify the agents in seven; in two, it was gram-positive, but there was no growth of germs. In our sample, the most frequently found germ in the blood cultures was $S$. aureus, which was found in three out of seven patients. Coagulase-negative Staphylococcus was isolated in two patients; and in one, the germ isolated was Staphylococcus spp. There was, also, one case of sepsis by yeast (Candida spp) in which the patient was under treatment for leprosy reaction. This patient presented loss of a large area of skin barrier and was under systemic corticotherapy. ${ }^{21}$

Parkins et al. (2007) reported the use of systemic steroids and empirical antibiotics inadequate to the invasive fungal infection and poor prognosis. This study drew attention to early diagnosis and the use of appropriate therapy for better chances of satisfactory treatment. ${ }^{22}$

In the work by Ahmed and Moy (1982) on death causes among patients with pemphigus, sepsis was found in nine out of 13 patients. The germ most frequently found was $S$. aureus, which was isolated in eight of the 13 patients. ${ }^{13}$

Studies on the antimicrobial susceptibility profile of $S$. aureus to diverse antibiotics, performed in China between 2003 and 2007, analyzed 984 strains of $S$. aureus isolated from pediatric patients with impetigo. The majority of the strains $(94.5 \%)$ were resistant to penicillin, followed by erythromycin $(86.2 \%)$ and clindamycin $(69.6 \%)$. The incidence of methicillinresistant Staphylococcus aureus (MRSA) associated with the community was $1.1 \%$, and all the strains were susceptible to ciprofloxacin. ${ }^{23}$

The most frequently used antibiotics in our study were ciprofloxacin and oxacillin, respectively, whose spectrum of coverage includes $S$. aureus, the pathogen most frequently isolated in secretion and blood cultures. E. coli was the most isolated bacteria in urine cultures and also presented sensitivity to ciprofloxacin. There are no data available in our country that contraindicate the use of ciprofloxacin or oxacillin as empirical antibiotic therapy for community-acquired infections. However, for patients presenting infections 48 hours after being hospitalized ( hospital infections), starting the treatment with 
ciprofloxacin or oxacillin would not be a good strategy, as the sample evaluated showed a significant chance of resistance to both types of antibiotics, which was also observed by Garner et al. (1988). ${ }^{24}$ There was antibiotic change after $36.8 \%$ of the requested cultures, emphasizing the need for research for more efficient coverage.

There are several studies in the literature reporting sepsis issues and their consequences in ITUs and other non-dermatological hospital areas. However, there are few studies on the subject in dermatology wards..$^{25-27} \mathrm{~A}$ study including 1,826 hospital patients reported the highest incidence of nosocomial infections in dermatology wards $(19.8 \%)$, compared with $13.1 \%$ inpatients of internal medicine wards. ${ }^{28}$

In the univariate analysis of this study, a high prevalence of sepsis was found among the inpatients of the dermatology ward $(7.6 \%)$, compared with that of the inpatients of the internal medicine ward. This higher prevalence, however, was not statistically significant $(\mathrm{p}=0.10)$. After the multivariate analysis, with the analysis of the main components and of hierarchical clustering, it was found that hospitalization in der- matology wards is related to a significant increase in the occurrence (OR 14.89) of sepsis. This was, possibly, due to factors previously assumed as premises, that is, large areas of skin loss, with impairment of the skin barrier and of the skin immune function, and the use of corticosteroids. ${ }^{13}$

\section{CONCLUSION}

This study observed a higher prevalence of sepsis in patients hospitalized in the dermatology ward compared with those in the internal medicine ward. It also found that bullous diseases were the dermatological conditions most frequently associated with the development of sepsis. It did not find an association between sepsis and diabetes mellitus and cancer.

It is clear that there is a need for the close monitoring of patients hospitalized in dermatology wards, especially of those using corticosteroids and presenting extensive loss of the skin barrier, since this group is particularly vulnerable to the occurrence of sepsis. Early identification and prompt establishment of an appropriate course of action may be the differential response in the treatment of this severe complication. 


\section{REFERENCES}

1. Bone RC, Balk RA, Cerra FB, Dellinger RP, Fein AM, Knaus WA, et al. Definitions for sepsis and organ failure and guidelines for the use of innovative therapies in sepsis. The ACCP/SCCM Consensus Conference Committee. American College of Chest Physicians/ Society of Critical Care Medicine. Chest. 1992;101:1644-55.

2. Balcl C, Sungurtekin H, Gürses E, Sungurtekin U, KaptanogluB.Usefulness of procalcitonin for diagnosis of sepsis in the intensive care unit. Crit Care. 2003;7:85-90.

3. Effect of high-dose glucocorticoid therapy on mortality in patients with clinical signs of systemic sepsis. The Veterans Administration Systemic Sepsis Cooperative Study Group. N Engl J Med. 1987;317:659-65.

4. Ding JG, Sun QF, Li KC, Zheng MH, Miao XH, Ni W, et al. Retrospective analysis of nosocomial infections in the intensive care unit of a tertiary hospital in China during 2003 and 2007. BMC Infect Dis. 2009;9:115.

5. Sharma VK, Asati DP, Khandpur S, Khilnani GC, Kapil A. Study of sepsis in dermatology ward: a preliminary report. Indian J Dermatol Venereol Leprol.. 2007;73: 367.

6. Hosmer DW, Lemeshow S. Applied logistic regression. New York: Wiley; 2000.

7. Ahmed AR. Clinical features of pemphigus. ClinDerm. 1983; 1:13-21.

8. Thomas M, Peter JV, Williams A, Job V, George R. Systemic inflammatory response syndrome in diseases of the skin. Postgrad Med J. 2010;86:83-8.

9. Brun-Buisson C. The epidemiology of the systemic inflammatory response. Intesive Care Med. 2000;26:S564-74.

10. Rangel-Frausto MS, Pittet D, Costigan M, Hwang T, Davis CS, Wenzel RP. The natural history of the systemic inflammatory response syndrome (SIRS). A prospective study. JAMA. 1995;273:117-23

11. Dremsizov T, Clermont G, Kellum JA, Kalassian KG, Fine MJ, Angus DC. Severe sepsis in community-acquired pneumonia: when does it happen and do systemic inflammatory response syndrome criteria help predict course? Chest. 2006;129: 968-78.

12. Harman KE, Albert S, Black MM; British Association of Dermatologists. Guidelines for the management of pemphigus vulgaris. Br J Dermatol.2003;149: 926-37.

13. Ahmed AR, Moy R. Death in pemphigus. J Am Acad Dermatol. 1982;7:221-8.

14. Huang YH, Kuo CF, Chen YH, Yang YW. Incidence, mortality, and causes of death of patients with pemphigus in Taiwan: A nationwide population-based study. J Invest Dermatol. 2012:132:92-7.

15. Angus DC, Linde-Zwirble WT, Lidicker J, Clermont G, Carcillo J, Pinsky MR Epidemiology of severe sepsis in the United States: Analysis of incidence, outcome, and associated costs of care. Crit Care Med. 2001;29:1303-10.

16. Hall MJ,Williams SN, DeFrances CJ, GolosinskiyA.Inpatient care for sepse or sepsis: A challenge for patients and hospitals. NCHS data brief, n. 62 Data from the National Health and Nutrition Examination Survey. Hyattsville: National Center for Health Statistics; 2011

17. Bertoni AG, Saydah S, Brancati FL. Diabetes and the risk of infection-related mortality in the US. Diabetes Care.2001;24:1044-9.

18. Carney DN, Fossieck BE, Jr, Parker RH, Minna JD. Bacteremia due to Staphylococcus aureus in patients with cancer: report on 45 cases in adults and review of the literature. Rev Infect Dis.1982;4:1-12.

19. Williams MD, Braun LA, Cooper LM, Johnston J, Weiss RV, Qual RL, et al. Hospitalized cancer patients with severe sepsis: analysis of incidence, mortality, and associated costs of care. Crit Care.2004;8:R291-8.

20. Nair PS, Moorthy PK, Yogiragan K. A study of mortality in dermatology.Indian J Dermatol VenereolLeprol.2005;71:23-5.

21. Puzniak L, Teutsch S, Powderly W, Polish L. Has the epidemiology of nosocomial candidemia changed? InfectControlHospEpidemiol.2004;25:628-33.

22. Parkins MD, Sabuda DM, Elsayed S, Laupland KB.Adequacy of empirical antifungal therapy and effect on outcome among patients with invasive Candida species infections.J AntimicrobChemother.2007;60:613-8.

23. Liu $Y$, Kong $F$, Zhang $X$, Brown M, Ma L, Yang $Y$. Antimicrobial susceptibility of Staphylococcus aureus isolated from children with impetigo in China from 2003 to 2007 shows community-associated methicillin-resistant Staphylococcus aureus to be uncommon and heterogeneous. Br J Dermatol.2009;16:1347-50.
24. Garner JS, Jarvis WR, Emori TG, Horan TC, Hughes JM. CDC definitions for nosocomial infections.Am J InfectControl. 1988;16:128-40.

25. Pittet D, Tarara D, Richard P. Nosocomial bloodstream infection in critically in patients. Excess length of stay, extra costs and attributable mortality.JAMA.1994;271: 1598601.

26. Garrouste-Orgeas M, Chevret S, Mainardi JL, Timsit JF, Misset B, Carlet J. A one year prospective study of nosocomial bacteremia in ICU and non ICU patients and its impact on patient outcome.J Hosplnfect. 2000;44:206-13.

27. Jang TN, Kuo BI, Shen SH, Fung CP, Lee SH, Yang TL, et al. Nosocomial gram-negative bacteremia in critically ill patients: Epidemiological characteristics and prognostic factors in 147 episodes. J Formos Med Assoc.1999;98:465-73.

28. Zang Y. A two-year prospective survey on nosocomial infections.Zhonghua Yi Xue Za Zhi.1991;71:253-6.

\author{
MAILING ADDRESS: \\ Michelle dos Santos Diniz \\ Av. Francisco Sales, 1.111 - Santa Efigênia \\ 30150-221 - Belo Horizonte - MG \\ Brazil \\ E-mail:michellesdmi@yahoo.com.br
}

How to cite this article: Almeida LMC, Diniz MS, Diniz LS, Pinto JM, Silva FCL. Comparative study of the prevalence of sepsis in patients admitted to dermatology and internal medicine wards. An Bras Dermatol. 2013;88(5):755-63. 